\title{
Capacity Choice and Government Regulation in a Vertical Industry
}

\author{
Junlong Chen', Yajie Wang ${ }^{2}$, Jiali Liu ${ }^{3, *}$ \\ ${ }^{1}$ School of Humanities and Law, Northeastern University \\ No. 177 Chuangxin Road, Hunnan District, Shenyang, Liaoning, China \\ E-mail.shikuangzhiwang@126.com \\ ${ }^{2}$ School of Economics, Peking University \\ No. 5 Yiheyuan Road, Haidian District, Beijing, China \\ E-mail.wangyj@stu.pku.edu.cn \\ ${ }^{3}$ Center for China Public Sector Economy Research of KRI, Jilin University; School of Economics, Jilin University \\ No. 2699 Qianjin Street, Gaoxin District, Changchun, Jilin, China \\ E-mail.liujiali@jlu.edu.cn \\ *Corresponding author
}

cross $^{\text {ref }}$ http://dx.doi.org/10.5755/j01.ee.31.5.25302

\begin{abstract}
This paper sets up an industry competition model consisting of two upstream enterprises and two downstream enterprises. Then we rely on the model to explore how non-regulation and different regulatory policies (maximizing the total profits of the upstream enterprises, the social welfare of the upstream industry or the overall social welfare) affect the following factors: the excess capacity, enterprise profits, consumer surpluses, social welfare in the upstream and downstream enterprises and the overall social welfare. The following conclusions are drawn from our research. First, whether and how the government regulates the capacity choice greatly affect the equilibrium outcomes, as well as the welfare distribution among the upstream enterprises, downstream enterprises, and consumers. The specific effects are dependent on market demand and enterprise cost. Second, the government should formulate its regulatory policies on capacity choice based on the overall social welfare of the entire supply chain. If the government aims to maximize the profits of the upstream enterprises, the social welfare of the downstream industry will be negatively affected. Third, excess capacity does not necessarily suppress social welfare. Under certain conditions, the worst scenario of excess capacity may occur under the pursuit of the maximal overall social welfare. Excess capacity may arise from various causes, rather than market competition or government regulation alone. Excess capacity cannot be attributed solely to government failure. These conclusions have some significance for optimizing capacity regulation policies.
\end{abstract}

Keywords: Capacity Choice; Government Regulation; Non-Regulation; Vertical Industry; Duopoly.

\section{Introduction}

Capacity choice bears directly on the cost, output, and profit of enterprises, thereby affecting consumer surplus and social welfare. This issue is a hot topic in academia, as evidenced by extensive research from both theoretical and empirical perspectives (Dagdeviren, 2016; Jain \& Bala, 2018; Murphy, 2017; Wen \& Sasaki, 2001). Starting from government regulation of capacity choice, this paper establishes a market competition model in a vertical industry and applies the model to explore the equilibrium results under non-regulation or different regulatory policies. The aim is to disclose how government capacity regulation affects upstream and downstream industries.

Duopoly models have been widely adopted in existing studies on capacity choice. Pure or mixed oligopoly markets have been constructed for multi-stage sequential game analysis, revealing how capacity is formed and affected by various factors (e.g., product differentiation, management authorization, competition type, enterprise ownership, and privatization). Nishimori \& Ogawa (2004) analyze the capacity choice of state-owned enterprises (SOEs) and private enterprises in China under a mixed oligopoly market with homogenous products. Lu \& Poddar (2006) investigate the capacity choice of enterprises under uncertain market demand. Targeting a mixed duopoly market with heterogeneous products, Ogawa (2006) and Barcena-Ruiz and Garzon (2010) study the capacity choice of enterprises under output competition and price competition. Lu and Poddar (2009) explore the capacity choice of a public enterprise and a private enterprise in a price-setting mixed duopoly. After classifying ownership and management rights, Tomaru et al. (2011) set up a mixed duopoly model to examine the capacity choice of SOEs and private enterprises under different types of authorization and discuss the effects of privatization on the type of management authorization and social welfare. Elhadj et al. (2012) investigate the quality and capacity choice in a vertical differentiation market with congestion. FernandezRuiz (2012) probes into the capacity choice of a public enterprise and a private enterprise in a mixed duopoly. Nakamura \& Saito (2013) study the capacity choice in a mixed duopoly with differentiated products, in which the private enterprise pursues its relative profit. Lavrutich (2017) studies the capacity choice in an existing duopoly market with uncertainties. Chen, Liu, Niu \& Zhu (2019) 
develop a duopoly model to disclose how heterogeneity and soft budget constraints affect the capacity choice and internal action mechanisms. Chen, Liu \& Qin (2019) analyze the relationship between corporate social responsibility and capacity choice. Chen, Xie \& Liu (2020) analyze the capacity sharing decision with different oligopolistic competition and government regulation. Chen, Wang \& Chu (2020) study the capacity choice considering capacity sharing. Following the above literature, we also use a duopoly model to analyze the capacity choice.

Few of these existing studies combine capacity choice with a vertical market, which is very common in the modern market economy. Ziss (1995) extends monopoly models to consider a vertically separated case. Lommerud et al. (2005) examine how a downstream merger affects profitability and find that it can be more profitable to take part in a merger than to be an outsider. Symeonidis (2010) analyzes the effects of a downstream merger in a differentiated oligopoly and believes that a downstream merger always reduces consumer surplus and overall welfare. In contrast, Ghosh et al. (2014) study the welfare effects of horizontal mergers and find that downstream mergers can increase welfare if input prices are reduced. Fanti (2016) analyzes the effects on social welfare of partial cross-participation at the ownership level between two downstream firms and believes that cross-participation reduces the degree of market competition and increases social welfare. Manasakis \& Vlassis (2013) propose that the downstream mode of competition in equilibrium is the outcome of independent implicit agreements between each downstream firm and its exclusive input supplier in each vertical chain. In this paper, we analyze the capacity choice in a vertical industry.

In contrast to existing research, this paper makes the following contributions. First, existing studies differ in the assumptions about the goal of capacity choice. Some studies assume that an enterprise attempts to maximize its profit without government regulation, while others hypothesize that the enterprise seeks to maximize social welfare through capacity choice under government regulation. ${ }^{1}$ These different assumptions give rise to the following questions: Is capacity regulation necessary, and what is the path for the government to regulate capacity choice? This paper attempts to give satisfactory answers to these questions.

Second, most existing studies address an isolated market, failing to place competitive enterprises in an industrial chain. In reality, industrial chains are extremely complex, but most studies discuss only the social welfare of one industry in an industrial chain without considering the upstream and downstream industries. Besides, most studies assume that government regulation attempts to maximize social welfare. This assumption cannot describe the actual objectives of government regulation in the real world. For example, the Chinese government has implemented strict capacity regulations in the steel, cement, coal and petrochemical industries, aiming to eliminate excess capacity. Through these regulations, upstream industries

\footnotetext{
1 Governments can take various direct or indirect measures to regulate capacity choice. The indirect measures include setting up SOEs that select capacity to maximize the social welfare (Nishimori \& Ogawa, 2004), guiding mixed ownership enterprises to pursue the weighted mean of profit and social welfare using the proportion of state-owned shares (Tomaru et
}

have seen rapid growth in the product price and profit, while downstream industries face very large price hike pressure. To address these two limitations, this paper attempts to establish a vertical industry market to examine how government regulation affects the capacity choice of upstream enterprises, which in turn influences upstream and downstream enterprises and consumer surpluses.

Third, the literature on vertical market competition generally considers the relationship between upstream and downstream enterprises as a bilateral oligopoly; that is, the upstream enterprise is the only supplier to the downstream enterprise, and the downstream enterprise is the sole consumer of the upstream enterprise. The products of upstream enterprises, such as power and tap water, are not entirely consumed by downstream enterprises. A large portion of the products is directly utilized by residents. Hence, our model is designed with the assumption that the market is under a unilateral monopoly: The upstream enterprise is the only supplier to the downstream enterprise, but the downstream enterprise is not the sole consumer of the upstream enterprise; the products from the upstream enterprise are also directly utilized by other market entities.

The purpose of this article is to build a capacity choice model in a vertical industry. On the one hand, this model improves the existing models and increases its realistic explanatory power. On the other hand, the article examines the effects of different capacity regulation policies and provides policy suggestions for governments. The remainder of this paper is organized as follows. Section 2 illustrates the construction of our model. Section 3 presents the equilibrium results of our model. Section 4 compares the following factors under non-regulation and different regulatory policies: excess capacity, enterprise profits, consumer surplus and social welfare in the vertical industry. Section 5 presents the conclusions.

\section{The Model}

We set up an industry competition model of two upstream enterprises and two downstream enterprises based on the following assumptions.

Assumption 1 In the upstream industry, the two enterprises denoted as Enterprise 1 and Enterprise 2 produce the entirely homogenous products. They participate in a Cournot competition. The market demand for upstream products can be expressed as (Chen, Wang, Gao \& Long, 2019; Chen, Liu, Mo \& Xu, 2019; Lee \& Wang, 2018), where $q_{1}$ and $q_{2}$ are the product outputs of Enterprises 1 and 2, respectively, $a>0$ is a constant, and the subscript $U$ means the upstream industry. The profit of each upstream enterprise can be described as $\pi_{i}=p_{U} q_{i}-c_{i}, i=1,2$. The cost of each upstream enterprise can be defined as $c_{i}=$ $m q_{i}+\left(x_{i}-q_{i}\right)^{2}$ (Nakamura \& Saito, 2013; Nakamura, 2014; Tomaru et al., 2009; Vives, 1986), where $x_{i}$ is the capacity of enterprise $i, q_{i}$ is the output of enterprise $i$, and $m(a>m>0)$ is a constant. The capacity is excessive if $x_{i}-q_{i}>0$ and insufficient if $x_{i}-q_{i}<0 .{ }^{2}$ The cost

al., 2011), and adopting subsidies and other soft budget constraints (Kornai, 1980). This paper assumes that government regulation directly intervenes in capacity, i.e., the government directly formulates the capacity of the enterprise.

2 In our paper, we assume that an enterprise makes the capacity choice 
function shows that the cost of an enterprise will be high if the capacity is too high or too low. The products of the upstream enterprises are both used as raw materials in the two downstream enterprises and consumed by other market entities. For example, the power generated by power plants drives production in downstream enterprises and satisfies the power demand of residents and other consumers.

Assumption 2 In the downstream industry, the two enterprises, denoted as Enterprise A and Enterprise B, output entirely homogenous products and participate in a Cournot competition. According to Assumption 1, the downstream enterprises use the products of the upstream enterprises as raw materials. For simplicity, it is further assumed that each unit of raw materials can lead to one unit of output. The market demand for downstream products can be expressed as $p_{D}=c-q_{A}-q_{B}\left(q_{A}+q_{B}<q_{1}+q_{2}\right)$, where $q_{A}$ and $q_{B}$ are the outputs of enterprises $\mathrm{A}$ and $\mathrm{B}$, respectively, $c>0$ is a constant, and the subscript $D$ means the downstream industry. The cost of each downstream enterprise can be described as $c_{j}=p_{U}=a-$ $q_{1}-q_{2}$. The profit of each downstream enterprise can be described as $\pi_{j}=\left(p_{D}-c_{j}\right) q_{j}$, where $j=A, B$.

Assumption 3 The social welfare of the upstream industry is assumed to be $S W_{U}=P S_{U}+C S_{U}$ (Chen, Tang $\&$ Liu, 2019; Chen, Liu, Long \& Luo, 2019), where $P S_{U}=$ $\pi_{1}+\pi_{2}$ and $C S_{U}=\frac{\left(q_{1}+q_{2}-q_{A}-q_{B}\right)^{2}}{2} .{ }^{3}$ Thus, the total social welfare of the upstream and downstream industries is the sum of the surplus of upstream enterprises, the surplus of downstream enterprises and the surplus of all consumers as follows:

$S W_{T}=\pi_{A}+\pi_{B}+\frac{\left(q_{1}+q_{2}-q_{A}-q_{B}\right)^{2}}{2}+\pi_{1}+\pi_{2}+\frac{\left(q_{A}+q_{B}\right)^{2}}{2}$.

Assumption 4 The government decides whether to and how to regulate the capacity choice of upstream enterprises. If it decides not to regulate the capacity choice, then each enterprise will pursue the maximal profit. If it decides to regulate the capacity choice, then the regulation strategies can be divided into three types based on the government's objective: maximizing the total profit of the two upstream enterprises, maximizing the social welfare of the upstream industry, and maximizing the social welfare of both the upstream and downstream industries. These three types of objectives reflect different policy orientations of the government. The pursuit of the overall social welfare of all industries is the best, but many regulation policies aim to solve practical problems in a certain industry field without giving full consideration to other related market players or industries in reality. For instance, the government may try to ensure the profit of the upstream industry through capacity regulation if the upstream enterprises face severe financial difficulties that affect the entire supply chain.

The above assumptions can be shown in Table 1.

without capacity constraints. In contrast to our paper, many scholars examine the effects of capacity constraints on enterprises. Esó et al. (2010) note that capacity constraints would lead to a symmetrical industrial structure and a higher output and consumer surplus. Nie \& Chen (2012) discuss the impact of capacity constraints on market size and price differences under Cournot and Stackelberg cases. Nie (2014) discusses the impact of capacity constraints on the firm size differences, price differences price dispersion and consumer surplus under different ownership systems. Tao et al. (2018) relax the capacity constraints and further study duopoly
Table1

The Assumptions of the Model

\begin{tabular}{|l|c|}
\hline \multicolumn{1}{|c|}{$\begin{array}{c}\text { The market } \\
\text { players }\end{array}$} & $\begin{array}{c}\text { Upstream: Enterprise 1 and Enterprise 2 } \\
\text { Downstream: Enterprise A and Enterprise B }\end{array}$ \\
\hline $\begin{array}{l}\text { The market } \\
\text { demand }\end{array}$ & $\begin{array}{l}\text { Upstream: } p_{U}=a-q_{1}-q_{2} \\
\text { Downstream: } p_{D}=c-q_{A}-q_{B}\end{array}$ \\
\hline $\begin{array}{l}\text { The cost of each } \\
\text { upstream } \\
\text { enterprise }\end{array}$ & $\mathrm{c}_{\mathrm{i}}=\mathrm{mq}_{\mathrm{i}}+\left(\mathrm{x}_{\mathrm{i}}-\mathrm{q}_{\mathrm{i}}\right)^{2}$ \\
\hline $\begin{array}{l}\text { The objective of } \\
\text { capacity choice } \\
\text { with non- } \\
\text { regulation non- }\end{array}$ & the maximal profit \\
\hline $\begin{array}{l}\text { The objectives of } \\
\text { capacity choice } \\
\text { with three types of } \\
\text { regulations }\end{array}$ & $\begin{array}{l}\text { (1) maximizing the total upstream profit } \\
\text { (2) maximizing the upstream social welfare }\end{array}$ \\
\hline $\begin{array}{l}\text { The social welfare } \\
\text { of the upstream } \\
\text { industry }\end{array}$ & \multicolumn{1}{|c|}{$S \mathrm{~W}_{\mathrm{U}}=\mathrm{PS}_{\mathrm{U}}+\mathrm{CS}_{\mathrm{U}}$} \\
\hline $\begin{array}{l}\text { The social welfare } \\
\text { of the vertical } \\
\text { industry the social welfare of both the }\end{array}$ & $S W_{T}=S W_{U}+\pi_{1}+\pi_{2}+\frac{\left(q_{A}+q_{B}\right)^{2}}{2}$ \\
\hline
\end{tabular}

Under the above assumptions, the upstream and downstream enterprises carry out a three-stage sequential game. In the first stage, the upstream enterprises reach their optimal capacity under the different regulatory policies of the government. In the second stage, the upstream enterprises determine their optimal outputs to maximize their profits. In the third stage, the downstream enterprises optimize their outputs through Cournot competition.

\section{Equilibrium Analysis}

The capacities and outputs of the upstream and downstream enterprises are investigated through backward induction.

The third stage of the game is discussed first. In this stage, the downstream enterprises determine their outputs for the maximal profits under the first-order conditions, which are expressed as

$$
\begin{aligned}
& \frac{\partial \pi_{A}}{\partial q_{A}}=-2 q_{A}+c-q_{B}-a+q_{1}+q_{2}=0 \\
& \frac{\partial \pi_{B}}{\partial q_{B}}=-q_{A}+c-2 q_{B}-a+q_{1}+q_{2}=0
\end{aligned}
$$

Thus, the equilibrium outputs of the downstream enterprises can be derived as

$$
q_{A}^{*}=q_{B}^{*}=\frac{c-a+q_{1}+q_{2}}{3}
$$

Next, the upstream enterprises determine their outputs to maximize their profits, according to the equilibrium outputs of the downstream enterprises. In this

models with a joint capacity constraint. Nie \& Wang (2019) address the effects of capacity constraints on innovation.

${ }^{3}$ In this paper, the overall social welfare function is constructed by assuming that the upstream products are both used by the downstream enterprises as raw materials and utilized by other consumers. By contrast, Fanti (2016) and Chen et al. (2017) assume that the upstream products are all consumed by the downstream enterprises. 
case, the output decisions of the two upstream enterprises must satisfy

$$
\begin{aligned}
& \frac{\partial \pi_{1}}{\partial q_{1}}=-4 q_{1}+a-q_{2}-m+2 x_{2}=0 \\
& \frac{\partial \pi_{2}}{\partial q_{2}}=-4 q_{2}+a-q_{1}-m+2 x_{1}=0
\end{aligned}
$$

Thus, the equilibrium outputs of the upstream enterprises can be derived as

$$
\begin{aligned}
& q_{1}=\frac{3 a-3 m+8 x_{1}-2 x_{2}}{15} \\
& q_{2}=\frac{3 a-3 m-2 x_{1}+8 x_{2}}{15}
\end{aligned}
$$

Formulas (6) and (7) show that the outputs of the upstream enterprises are constrained by their capacities.

Finally, the equilibrium results are explored under nonregulation and different regulatory policies (the three policy objectives) as follows:

\section{Non-Regulation}

To maximize their profits, the upstream enterprises must satisfy the following conditions for capacity choice:

$$
\begin{aligned}
& \frac{\partial \pi_{1}}{\partial x_{1}}=\frac{96 a-96 m-194 x_{1}-64 x_{2}}{225}=0 \\
& \frac{\partial \pi_{2}}{\partial x_{2}}=\frac{96 a-96 m-64 x_{1}-194 x_{2}}{225}=0
\end{aligned}
$$

Thus, the equilibrium capacities of the upstream enterprises can be derived as

$$
x_{1}^{*}=x_{2}^{*}=\frac{16 a-16 m}{43}
$$

To ensure production, the following must be satisfied: $p_{U}^{*}=\frac{13 a+30 m}{43}>0, \pi_{1}^{*}=\pi_{2}^{*}=\frac{194(a-m)^{2}}{1849}>0, p_{D}^{*}-c_{j}^{*}=$ $\frac{43 c-13 a-30 m}{129}$ and $q_{1}^{*}+q_{2}^{*}-\left(q_{A}^{*}+q_{B}^{*}\right)=\frac{116 a-86 c-30 m}{129}>$ 0 . Thus, we can deduce that $\frac{13 a+30 m}{43}<c<\frac{58 a-15 m}{43}$.

Lemma 1 When the government does not regulate the capacity choice, i.e., the enterprises are allowed to maximize their profits, the equilibrium results under the condition $\frac{13 a+30 m}{43}<c<\frac{58 a-15 m}{43}$ can be described as

$$
\begin{aligned}
& x_{1}^{*}=x_{2}^{*}=\frac{16 a-16 m}{43}, q_{1}^{*}=q_{2}^{*}=\frac{15 a-15 m}{43}, q_{A}^{*}=q_{B}^{*}= \\
& \frac{43 c-13 a-30 m}{129}, \quad \pi_{1}^{*}=\pi_{2}^{*}=\frac{194(a-m)^{2}}{1849}, \quad \pi_{A}^{*}=\pi_{B}^{*}= \\
& \left(\frac{43 c-13 a-30 m}{129}\right)^{2}, C S_{U}^{*}=\frac{450(a-m)^{2}}{1849}, C S_{D}^{*}=\frac{2(13 a-43 c+30 m)^{2}}{16641}, \\
& S W_{U}^{*}=\frac{838(a-m)^{2}}{1849}, S W_{D}^{*}=4\left(\frac{43 c-13 a-30 m}{129}\right)^{2}, \text { and } S W_{T}^{*}= \\
& \frac{3632 a^{2}-4816 a c-2448 a m+3689 c^{2}-2580 c m+2514 m^{2}}{5547} .
\end{aligned}
$$

\section{Capacity Regulation}

Assuming that the government implements capacity regulation, this subsection examines the capacity, output and profit of the entire supply chain; the consumer surplus; and the social welfare under three conditions: maximizing the total profit of the upstream enterprises, maximizing the social welfare of the upstream industry, and maximizing the overall social welfare of both the upstream and downstream industries.

If the government pursues the maximal total profit of the upstream enterprises, the equilibrium capacities of the upstream enterprises can be described as

$$
x_{1}^{* *}=x_{2}^{* *}=\frac{4 a-4 m}{17}
$$

To make the enterprises willing to conduct production, the following conditions must be satisfied: $p_{U}^{* *}=\frac{7 a+10 m}{17}>$ $0, \pi_{1}^{* *}=\pi_{2}^{* *}=\frac{2(a-m)^{2}}{17}>0, p_{D}^{* *}-c_{j}^{* *}=\frac{17 c-7 a-10 m}{51}>0$, and $q_{1}^{* *}+q_{2}^{* *}-\left(q_{A}^{* *}+q_{B}^{* *}\right)=\frac{44 a-34 c-10 m}{51}>0$. Thus, we can obtain $\frac{7 a+10 m}{17}<c<\frac{22 a-5 m}{17}$.

Lemma 2 When the government pursues the maximal total profit of the upstream enterprises, the equilibrium outcomes under the condition $\frac{7 a+10 m}{17}<c<\frac{22 a-5 m}{17}$ can be described as: $x_{1}^{* *}=x_{2}^{* *}=\frac{4 a-4 m}{17}, q_{1}^{* *}=q_{2}^{* *}=\frac{5 a-5 m}{17}$, $q_{A}^{* *}=q_{B}^{* *}=\frac{17 c-7 a-10 m}{51}, \quad \pi_{1}^{* *}=\pi_{2}^{* *}=\frac{2(a-m)^{2}}{17}, \quad \pi_{A}^{* *}=$ $\pi_{B}^{* *}=\left(\frac{17 c-7 a-10 m}{51}\right)^{2} \quad, \quad C S_{U}^{* *}=\frac{50(a-m)^{2}}{289} \quad, \quad C S_{D}^{* *}=$ $\frac{2(7 a-17 c+10 m)^{2}}{2601} \quad, \quad S W_{U}^{* *}=\frac{118(a-m)^{2}}{289} \quad, \quad S W_{D}^{* *}=$ $4\left(\frac{17 c-7 a-10 m}{51}\right)^{2}$ and

$S W_{T}^{* *}=\frac{592 a^{2}-816 a c-368 a m+578 c^{2}-340 c m+354 m^{2}}{867}$.

To maximize the social welfare of the upstream industry $S W_{U}$, the equilibrium capacities of the upstream enterprises should satisfy

$$
x_{1}^{* * *}=x_{2}^{* * *}=\frac{6 a-6 m}{13}
$$

Since $p_{U}^{* * *}=\frac{3 a+10 m}{13}>0, \pi_{1}^{* * *}=\pi_{2}^{* * *}=\frac{14(a-m)^{2}}{169}>$ $0, \quad p_{D}^{* * *}-c_{j}^{* * *}=\frac{13 c-3 a-10 m}{39}>0$, and $q_{1}^{* * *}+q_{2}^{* * *}-$ $\left(q_{A}^{* * *}+q_{B}^{* * *}\right)=\frac{36 a-26 c-10 m}{39}>0$, we have $\frac{3 a+10 m}{13}<c<$ $\frac{18 a-5 m}{13}$.

Lemma 3 When the government pursues the maximal social welfare of the upstream industry, the equilibrium results under the condition $\frac{3 a+10 m}{13}<c<\frac{18 a-5 m}{13}$ can be described as: $x_{1}^{* * *}=x_{2}^{* * *}=\frac{6 a-6 m}{13}, q_{1}^{* * *}=q_{2}^{* * *}=\frac{5 a-5 m}{13}$, $q_{A}^{* * *}=q_{B}^{* * *}=\frac{13 c-3 a-10 m}{39} \quad, \quad \pi_{1}^{* * *}=\pi_{2}^{* * *}=\frac{14(a-m)^{2}}{169}$, $\pi_{A}^{* * *}=\pi_{B}^{* * *}=\left(\frac{13 c-3 a-10 m}{39}\right)^{2}, C S_{U}^{* * *}=\frac{50(a-m)^{2}}{169}, C S_{D}^{* * *}=$ $\frac{2(3 a-13 c+10 m)^{2}}{1521} \quad, \quad S W_{U}^{* * *}=\frac{6(a-m)^{2}}{13} \quad, \quad S W_{D}^{* * *}=$ $4\left(\frac{13 c-3 a-10 m}{39}\right)^{2}$ and

$$
S W_{T}^{* * *}=\frac{24 a^{2}-32 a c-16 a m+26 c^{2}-20 c m+18 m^{2}}{39} .
$$

To maximize the total social welfare of the upstream and downstream industries $S W_{T}$, the equilibrium capacities of the upstream enterprises can be described as 


$$
x_{1}^{* * * *}=x_{2}^{* * * *}=\frac{8 a+10 c-6 m}{39}
$$

To make the enterprises willing to conduct production, the following conditions must be satisfied:

$$
\begin{aligned}
& p_{U}^{* * * *}=\frac{17 a+30 m-8 c}{39}>0 \quad \pi_{i}^{* * * *}= \\
& \frac{178 a^{2}-372 a m+16 a c+126 m^{2}+120 c m-68 c^{2}}{1521}>0, \\
& p_{D}^{* * * *}-c_{j}^{* * * *}=\frac{47 c-17 a-30 m}{117}>0 \text { and } q_{1}^{* * * *}+q_{2}^{* * * *}- \\
& \left(q_{A}^{* * * *}+q_{B}^{* * * *}\right)=\frac{100 a-70 c-30 m}{117}>0 \text {. Thus, we have } \\
& \frac{17 a+30 m}{47}<c<\frac{10 a-3 m}{7} .
\end{aligned}
$$

Lemma 4 When the government pursues the maximal social welfare, the equilibrium results under the condition $\frac{17 a+30 m}{47}<c<\frac{10 a-3 m}{7}$ can be described as

$$
\begin{aligned}
& x_{1}^{* * * *}=x_{2}^{* * * *}=\frac{8 a+10 c-6 m}{39}, q_{1}^{* * * *}=q_{2}^{* * * *} \frac{11 a-15 m+4 c}{13} \\
& q_{A}^{* * * *}=q_{B}^{* * * *}=\frac{47 c-17 a-30 m}{117}, \\
& \pi_{1}^{* * * *}=\pi_{2}^{* * * *}=\frac{178 a^{2}-372 a m+16 a c+126 m^{2}+120 c m-68 c^{2}}{1521}, \\
& \pi_{A}^{* * * *}=\pi_{B}^{* * * *}=\left(\frac{47 c-17 a-30 m}{117}\right)^{2}, C S_{U}^{* * * *}=\frac{2(11 a+4 c-15 m)^{2}}{1521} \\
& C S_{D}^{* * * *}=\frac{2(17 a-47 c+30 m)^{2}}{13689}, S W_{U}^{* * * *}= \\
& \frac{46 a^{2}-108 a m+16 a c+54 m^{2}-8 c^{2}}{117} \\
& S W_{D}^{* * *}=4\left(\frac{47 c-17 a-30 m}{117}\right)^{2}, \text { and } S W_{T}^{* * * *}= \\
& \frac{80 a^{2}-112 a c-48 a m+86 c^{2}-60 c m+54 m^{2}}{117}
\end{aligned}
$$

\section{Comparative Analysis}

This section mainly compares the excess capacity, enterprise profits, consumer surpluses and social welfare in the industry under different objectives of capacity regulation. When facing different regulatory policies, the enterprises are willing to conduct production under different conditions. To facilitate the comparisons, the ranges of $\mathrm{c}$ and $\mathrm{m}$ are limited to $\frac{7 a+10 m}{17}<c<\frac{22 a-5 m}{17}$.

\section{Comparison of Excess Capacities}

The excess capacities under different objectives of capacity choice are contrasted based on Lemmas 1 4.

Proposition 1 When the capacity regulation aims to maximize the total profit of the upstream enterprises, the capacity is insufficient $\left(x_{i}^{* *}-q_{i}^{* *}<0\right)$. When the capacity regulation aims to maximize the profit of individual enterprises (non-regulation) or the social welfare of the upstream industry (regulation), the capacity is excessive $\left(x_{i}^{*}-q_{i}^{*}=\frac{a-m}{43}>0, x_{i}^{* * *}-q_{i}^{* * *}=\frac{a-m}{13}>0\right)$, and $x_{i}^{* * *}-$ $q_{i}^{* * *}>x_{i}^{*}-q_{i}^{*}$. When the capacity regulation aims to maximize the overall social welfare, $x_{i}^{* * *}-q_{i}^{* * *}>x_{i}^{*}-$ $q_{i}^{*}>0>x_{i}^{* * * *}-q_{i}^{* * * *}=\frac{2 c-a-m}{13}>x_{i}^{* *}-q_{i}^{* *}$ if $\frac{7 a+10 m}{17}<$

4 For example, Dixit \& Stiglitz (1977), Dagdeviren \& Mahran (2010) and Robles (2011) attribute excess capacity to market structure and enterprise behaviour. Basu (1996), Fagnart et al. (1999) and Basu et al. (2001) $c<\frac{a+m}{2} ; \quad x_{i}^{* * *}-q_{i}^{* * *}>x_{i}^{*}-q_{i}^{*}>x_{i}^{* * * *}-q_{i}^{* * * *}>0>$ $x_{i}^{* *}-q_{i}^{* *}$ if $\frac{a+m}{2}<c<\frac{28 a+15 m}{43} ; x_{i}^{* * *}-q_{i}^{* * *}>x_{i}^{* * * *}-$ $q_{i}^{* * * *}>x_{i}^{*}-q_{i}^{*}>0>x_{i}^{* *}-q_{i}^{* *}$ if $\frac{28 a+15 m}{43}<c<a$; and $x_{i}^{* * * *}-q_{i}^{* * * *}>x_{i}^{* * *}-q_{i}^{* * *}>x_{i}^{*}-q_{i}^{*}>0>x_{i}^{* *}-q_{i}^{* *} \quad$ if $a<c<\frac{22 a-5 m}{17}$.

\section{Proof: See Appendix A}

There are two conflicting views on the root causes of excess capacity: market failure and government failure. ${ }^{4}$ Proposition 1 sheds new light on this conflict. Government regulation of enterprise capacities affects the degree of excess capacity. If the government does not regulate the capacity choice of enterprises, excess capacity will be the inevitable outcome. Since it exists even without government regulation, excess capacity can be considered unavoidable in a market economy. Under government regulation, the excess capacity will increase if the social welfare of the upstream industry is the only objective; the capacity will become insufficient if the profits of the upstream enterprises are the only objective (this can explain the problems arising in China's de-capacity process); and both excess and insufficient capacities may occur if the overall social welfare is the only objective, where the capacity is more likely to be insufficient if $c-a$ is small and $m$ is large, which implies that upstream and downstream market functions and marginal fixed cost have impacts on capacity. When the price ceiling of the upstream enterprises is lower than that of the downstream enterprises $\left(a<c<\frac{22 a-5 m}{17}\right)$, the overall social welfare is the highest but the overcapacity is the most serious, and the government should maximize the total social welfare of the upstream and downstream industries with serious overcapacity. Otherwise, the government needs to achieve a high degree of excess capacity to maximize social welfare. In summary, there is no inevitable positive or negative correlation between government regulation and excess capacity, which is related to the market situation and the conditions of enterprises. The policy implication is that capacity regulation does not necessarily aim to eliminate excess capacity, and under certain circumstances, moderate overcapacity is conducive to achieving regulatory goals.

\section{Comparison between the Profits of the Upstream and Downstream Enterprises}

Proposition 2 can be deduced by comparing the profits of the upstream and downstream enterprises under different objectives of government regulation.

Proposition 2 If $\frac{7 a+10 m}{17}<c<\frac{28 a+15 m}{43}$, then $\pi_{i}^{* *}>$ $\pi_{i}^{* * * *}>\pi_{i}^{*}>\pi_{i}^{* * *}$ and $\pi_{j}^{* * *}>\pi_{j}^{*}>\pi_{j}^{* * * *}>\pi_{j}^{* *} ;$ if $\frac{28 a+15 m}{43}<c<a$, then $\pi_{i}^{* *}>\pi_{i}^{*}>\pi_{i}^{* * * *}>\pi_{i}^{* * *}$ and

consider excess capacity a result of the cyclical fluctuations in the economy. Kornai (1980) and Yu \& Lu (2015) suggest that government behaviour is the cause of excess capacity. 
$\pi_{j}^{* * *}>\pi_{j}^{* * * *}>\pi_{j}^{*}>\pi_{j}^{* *} ;$ and if $a<c<\frac{22 a-5 m}{17}$, then $\pi_{i}^{* *}>\pi_{i}^{*}>\pi_{i}^{* * *}>\pi_{i}^{* * * *}$ and $\pi_{j}^{* * * *}>\pi_{j}^{* * *}>\pi_{j}^{*}>\pi_{j}^{* *}$.

\section{Proof: See Appendix B}

Proposition 2 shows that the regulatory policies on capacity directly affect the profits of the upstream enterprises. The highest profits can be achieved if the policies pursue the maximal total profits of the upstream enterprises, and the profits will be relatively low if the enterprises can select their capacities. This is similar to the prisoner's dilemma. The profits will be even lower if the social welfare of upstream consumers is taken into account. When the policies pursue the overall social welfare, the ranking of the profits of the upstream enterprises will be very uncertain, depending on the values of $a, c$ and $m$, which reflect upstream and downstream market functions and marginal fixed cost, respectively. But these profits will be lower than those when the policies pursue the maximal total profits of the upstream enterprises. The profits of the downstream enterprises will change in the opposite direction to those of the upstream enterprises, revealing the negative correlation between the upstream and downstream enterprises in profits. If the price ceiling of the upstream enterprises is higher than that of the downstream enterprises $(c<a)$, the regulation that maximizes the profits of the upstream enterprises is most beneficial to the upstream enterprises, and regulation that maximizes the social welfare of the upstream enterprises is most beneficial to the downstream enterprises. Otherwise, the regulation that maximizes the overall social welfare is most beneficial to the downstream enterprises. The policy implication is that differences in regulatory policy objectives and market conditions directly affect the profit distribution of the upstream and downstream enterprises.

\section{Comparison between the Consumer Surpluses of the Upstream and Downstream Industries}

Proposition 3 can be deduced through the consumer surpluses of the upstream and downstream industries under different objectives of government regulation.

Proposition 3 If $\frac{7 a+10 m}{17}<c<\frac{28 a+15 m}{43}$, then $C S_{U}^{* * *}>$ $C S_{U}^{*}>C S_{U}^{* * * *}>C S_{U}^{* *}$ and $C S_{D}^{* * *}>C S_{D}^{*}>C S_{D}^{* * * *}>C S_{D}^{* *}$. If $\frac{28 a+15 m}{43}<c<a$, then $C S_{U}^{* * *}>C S_{U}^{* * * *}>C S_{U}^{*}>C S_{U}^{* *}$ and $C S_{D}^{* * *}>C S_{D}^{* * * *}>C S_{D}^{*}>C S_{D}^{* *}$. If $a<c<\frac{22 a-5 m}{17}$, then $\quad C S_{U}^{* * * *}>C S_{U}^{* * *}>C S_{U}^{*}>C S_{U}^{* *}$ and $C S_{D}^{* * * *}>$ $C S_{D}^{* * *}>C S_{D}^{*}>C S_{D}^{* *}$.

\section{Proof: See Appendix C}

According to Proposition 3, the consumer surpluses change consistently in the upstream and downstream industries, indicating a positive correlation between the two factors. The consumer surpluses in the upstream and downstream industries will be minimized if the total profits of the upstream enterprises are the objective. This means that the pursuit of profits is harmful to consumer surplus. The consumer surpluses are not minimized without regulation and are higher than those under the pursuit of the overall social welfare if $\frac{7 a+10 m}{17}<c<\frac{28 a+15 m}{43}$. Thus, free competition in the market does not necessarily lead to the worst social welfare for consumers. In most cases (except $a<c<\frac{22 a-5 m}{17}$ ), the highest social welfare for consumers will occur under the pursuit of the maximal social welfare of the upstream industry, rather than the pursuit of the maximal overall social welfare. When $a<c<\frac{22 a-5 m}{17}$, the consumer surplus can be maximized through the pursuit of the maximal overall social welfare. Compared with the pursuit of the maximal total profit of the upstream enterprises or non-regulation, the pursuit of the maximal social welfare of the upstream industry or the overall social welfare can promote the consumer surplus. The price ceilings of the upstream and downstream enterprises and the marginal fixed cost ( $a, c$ and $m$, respectively) affect the comparison of consumer surplus. The policy implication is that incorporating the consumer surplus into the capacity regulation goal will help increase the consumer surplus.

\section{Comparison of the Social Welfare of the Upstream Industry}

The social welfare of the upstream industry is compared under different objectives of government regulation.

Proposition 4 If $\frac{7 a+10 m}{17}<c<\frac{28 a+15 m}{43}$, then $S W_{U}^{* * *}>S W_{U}^{*}>S W_{U}^{* * * *}>S W_{U}^{* *} \quad$.If $\quad \frac{28 a+15 m}{43}<c<$ $\frac{22 a-5 m}{17}$, then $S W_{U}^{* * *}>S W_{U}^{* * * *}>S W_{U}^{*}>S W_{U}^{* *}$.

\section{Proof: See Appendix D.}

As shown in Proposition 4, the highest social welfare of the upstream industry will be obtained under the pursuit of the maximal social welfare of the upstream industry, and the pursuit of the maximal total profit of the upstream enterprises can obtain the lowest social welfare of the upstream industry. The results show that the social welfare of the upstream industry increases with the number of entities being considered. This derivation is logical. When regulatory policy aims to maximize the overall social welfare, the social welfare of the upstream industry will fall in the medium range. Depending on the values of $a, c$ and $m$, the social welfare of the upstream industry, in this case, maybe greater than, equal to or lower than that under the pursuit of the maximal profit of individual enterprises. When the price ceiling of the downstream enterprises is lower $\left(\frac{10 a+7 m}{17}<c<\frac{28 a+15 m}{43}\right)$, non-regulation is more beneficial to the upstream industry than regulation maximizing the overall social welfare. The policy implication is that the implementation of regulations will not necessarily increase the social welfare of the upstream industry, and the social welfare of the upstream industry will not necessarily decrease even if the social welfare of the downstream industry is considered. 


\section{Comparison of the Social Welfare of the Downstream Industry}

Proposition 5 can be derived by comparing the social welfare of the downstream industry under different objectives of government regulation.

Proposition 5 If $\frac{7 a+10 m}{17}<c<\frac{28 a+15 m}{43}$, then $S W_{D}^{* * *}>S W_{D}^{*}>S W_{D}^{* * * *}>S W_{D}^{* *}$; if $\frac{28 a+15 m}{43}<c<a$, then $S W_{D}^{* * *}>S W_{D}^{* * * *}>S W_{D}^{*}>S W_{D}^{* *} ;$ and if $a<c<$ $\frac{22 a-5 m}{17}$, then $S W_{D}^{* * * *}>S W_{D}^{* * *}>S W_{D}^{*}>S W_{D}^{* *}$.

\section{Proof: See Appendix E}

Proposition 5 shows that the social welfare of the downstream industry will be minimized when regulatory policy attempts to maximize the total profits of the upstream enterprises. This value will increase under non-regulation and further grow under the pursuit of the maximal social welfare of the upstream industry. The results can be explained as follows. The profits of the upstream enterprises increase at the cost of consumer surplus, and the consumer surplus in the upstream industry directly affects the social welfare of the downstream industry. Therefore, the total social welfare of the downstream industry can be enhanced by improving the consumer surplus of the upstream industry. The pursuit of the maximal overall social welfare has uncertain impacts on the social welfare of the downstream industry, which is associated with the price ceilings of enterprises. Under this strategy, the social welfare of the downstream industry may be even lower than that under the pursuit of the maximal social welfare of the upstream industry or the maximal profit of individual enterprises in the upstream industry. Therefore, capacity regulation based on the overall social welfare may not always bolster the social welfare of the downstream industry, relying on the market demand in the vertical industry.

\section{Comparison of the Overall Social Welfare}

Finally, Proposition 6 can be derived by comparing the overall social welfare under different objectives of government regulation.

$$
\begin{aligned}
& \text { Proposition } 6 \text { If } \frac{7 a+10 m}{17}<c<\frac{19 a+15 m}{34} \text {, then } \\
& S W_{T}^{* * * *}>S W_{T}^{*}>S W_{T}^{* *}>S W_{T}^{* * *} ; \text { if } \frac{19 a+15 m}{34}<c< \\
& \frac{71 a+15 m}{86}, \text { then } S W_{T}^{* * * *}>S W_{T}^{*}>S W_{T}^{* * *}>S W_{T}^{* *} ; \\
& \text { and if } \frac{71 a+15 m}{86}<c<\frac{22 a-5 m}{17} \text {, then } S W_{T}^{* * * *}>S W_{T}^{* * *}> \\
& S W_{T}^{*}>S W_{T}^{* *} .
\end{aligned}
$$

\section{Proof: See Appendix F}

As shown in Proposition 6, the overall social welfare will be optimized if the government pursues the maximal overall social welfare and will be damaged if the policy orientation deviates from this objective. Judging by the overall social welfare, the pursuit of the maximal profit of individual enterprises in the upstream industry is better than the pursuit of the total profits of the upstream enterprises.
The values of $a, c$ and $m$ determine how the overall social welfare of the upstream and downstream industries is affected by the pursuit of the maximal social welfare in the upstream industry. Also, non-regulation will not produce overall social welfare lower than those of all three conditions of capacity regulation. This means improper regulation which implies government failure is worse than letting enterprises select their capacities, and market failure is not a sufficient condition for government intervention. The policy implication is that the government must decide whether to adopt regulations and what regulatory policies to choose according to market conditions. If corruption and other government failures are taken into consideration, government regulation should be more cautious.

In summary, the comparison results of the equalization results are shown in Figure 1 and Figure 2.

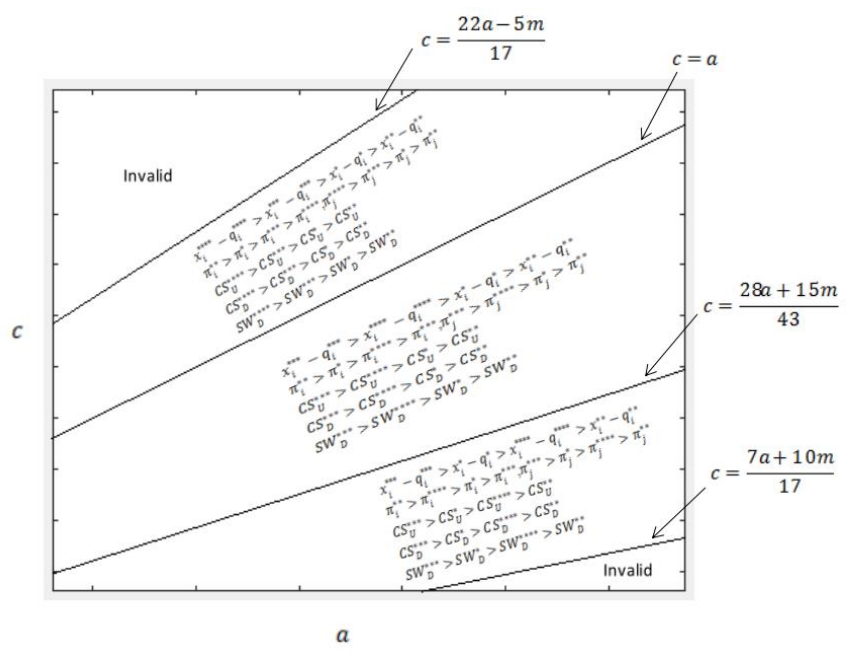

Figure 1. The Comparison Results of Excess Capacities, the Profits, Consumer Surpluses, the Upstream Social Welfare and the Downstream Social Welfare

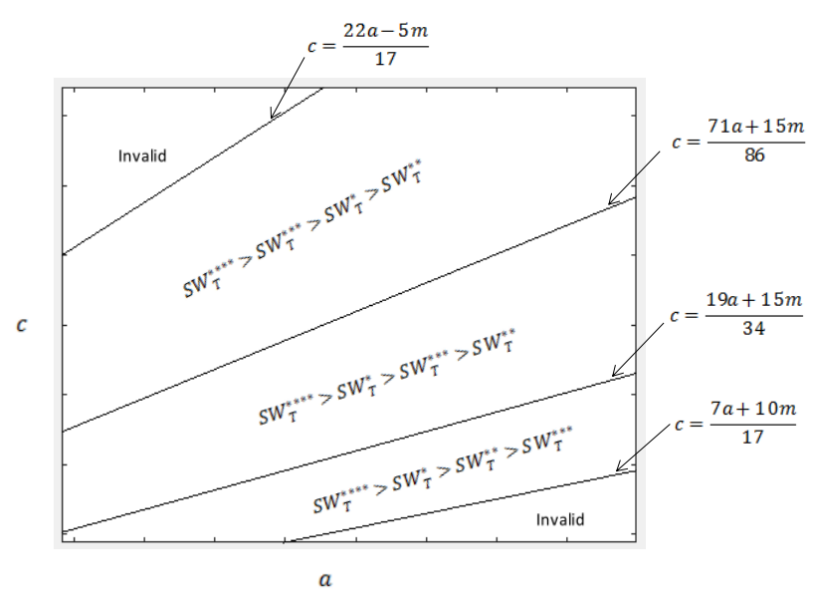

Figure 2. The Comparison Results of the Overall Social Welfare

\section{Conclusions}

This paper sets up an industry competition model consisting of two upstream enterprises and two downstream enterprises to explore how regulatory policies affect the excess capacity, enterprise profits, consumer surpluses and social welfare in the industry and the overall social welfare. The following conclusions are drawn from our research. 
First, each type of capacity choice has significant impacts on the enterprise profits, consumer surpluses and social welfare in the vertical industry, and the impacts are closely correlated with each other. Thus, the government needs to decide whether and how to conduct capacity regulation. The government's regulatory behaviour affects the welfare distribution among upstream enterprises, downstream enterprises and consumers, and the specific effects are dependent on the values of $a, c$ and $m$, which reflect the price ceilings of upstream and downstream enterprises and the marginal fixed cost, respectively. The relationship between the price ceilings of the upstream and downstream enterprises should be taken into consideration when the government makes decisions regarding regulation implementation. Besides, the effect of regulatory policies should be assessed according to local conditions, as well as the market demand and enterprise cost in the upstream and downstream industries.

Second, the government should formulate its regulatory policy on capacity choice based on the overall welfare of the upstream and downstream industries. The social welfare of the downstream industry will be undermined if the government overemphasizes the profits of the upstream enterprises. The pursuit of maximizing the overall social welfare is most reasonable, but such regulation is often very difficult to achieve in reality. The government may put forward favourable policies for the profits of the upstream enterprises only under special conditions such as severe excess capacity. Such policies aim to address the short-term stability of the upstream industry. However, the overall social welfare of the entire supply chain must be prioritized in the long run. Besides, improper government regulation often leads to bad consequences such as corruption and severe overcapacity in some countries, that is, government failure. Therefore, regulations cannot be implemented blindly; the government should also adopt a variety of measures to regulate regulatory behaviour, and information efficiency is very important. For example, an effective way to fight corruption is digital public services (FaneaIvanovici et al., 2019).

Third, excess capacity does not necessarily suppress social welfare. Under certain conditions, the worst scenario of excess capacity may occur under the pursuit of the maximal overall social welfare. Thus, it is irrational to pursue de-capacity blindly. Excess capacity may arise from various causes, rather than market competition or government regulation alone. The causes should be identified accurately to ensure the efficiency of regulatory policies. Capacity policy needs to be tailored to local conditions, focusing on the overall welfare of the entire industrial chain, without taking extreme de-capacity measures. De-capacity for de-capacity may cause severe market fluctuations and harm social welfare. This is of special guiding significance for the countries with excess capacity like China.

These conclusions have certain policy implications for governments to formulate scientific capacity regulation policies. However, this paper does not consider capacity constraints, product differentiation, multi-enterprise competition, and other oligopoly models (e.g., Stackelberg and Cournot models), and the model can be expanded in the future. Besides, the situation considered in this article is a situation where the downstream industry shares the upstream capacity, which can be extended to capacity sharing in the same industry.

\section{Appendix A: Proof of Proposition 1}

The following can be derived if $\mathrm{a}>\mathrm{m}$ and $\frac{7 \mathrm{a}+10 \mathrm{~m}}{17}<\mathrm{c}<\frac{22 \mathrm{a}-5 \mathrm{~m}}{\mathrm{a}-\mathrm{17}}$ :

$$
\begin{aligned}
& \mathrm{x}_{\mathrm{i}}^{*}-\mathrm{q}_{\mathrm{i}}^{*}=\frac{\mathrm{a}-\mathrm{m}}{43}>0, \mathrm{x}_{\mathrm{i}}^{* *}-\mathrm{q}_{\mathrm{i}}^{* *}=\frac{\mathrm{m}-\mathrm{a}}{17}<0, \mathrm{x}_{\mathrm{i}}^{* * *}-\mathrm{q}_{\mathrm{i}}^{* * *}=\frac{\mathrm{a}-\mathrm{m}}{13}>0 \text {, and } \mathrm{x}_{\mathrm{i}}^{* * *}-\mathrm{q}_{\mathrm{i}}^{* * *}>\mathrm{x}_{\mathrm{i}}^{*}-\mathrm{q}_{\mathrm{i}}^{*} . \\
& \text { If } \frac{7 \mathrm{a}+10 \mathrm{~m}}{17}<\mathrm{c}<\frac{\mathrm{a}+\mathrm{m}}{2}, \text { then } \mathrm{x}_{\mathrm{i}}^{* * * *}-\mathrm{q}_{\mathrm{i}}^{* * * *}=\frac{2 \mathrm{c}-\mathrm{a}-\mathrm{m}}{13}<0 \text { and }\left(\mathrm{x}_{\mathrm{i}}^{* *}-\mathrm{q}_{\mathrm{i}}^{* *}\right)-\left(\mathrm{x}_{\mathrm{i}}^{* * * *}-\mathrm{q}_{\mathrm{i}}^{* * * *}\right)=\frac{30 \mathrm{~m}+4 \mathrm{a}-34 \mathrm{c}}{221}<0 .
\end{aligned}
$$

Thus, we have $x_{i}^{* * * *}-q_{i}^{* * * *}>x_{i}^{* *}-q_{i}^{* *}$.

$$
\text { If } \frac{a+m}{2}<c<\frac{28 a+15 m}{43} \text {, then } x_{i}^{* * * *}-q_{i}^{* * * *}=\frac{2 c-a-m}{13}>0 \text { and }\left(x_{i}^{*}-q_{i}^{*}\right)-\left(x_{i}^{* * * *}-q_{i}^{* * * *}\right)=\frac{30 m+56 a-86 c}{559}>0 \text {. }
$$

Thus, we have $x_{i}^{* * *}-q_{i}^{* * *}>x_{i}^{*}-q_{i}^{*}>x_{i}^{* * * *}-q_{i}^{* * * *}>0$.

$$
\text { If } \frac{28 \mathrm{a}+15 \mathrm{~m}}{43}<\mathrm{c}<\mathrm{a} \text {, then } \mathrm{x}_{\mathrm{i}}^{* * * *}-\mathrm{q}_{\mathrm{i}}^{* * * *}=\frac{2 \mathrm{c}-\mathrm{a}-\mathrm{m}}{13}>0, \quad\left(\mathrm{x}_{\mathrm{i}}^{*}-\mathrm{q}_{\mathrm{i}}^{*}\right)-\left(\mathrm{x}_{\mathrm{i}}^{* * * *}-\mathrm{q}_{\mathrm{i}}^{* * * *}\right)=\frac{30 \mathrm{~m}+56 \mathrm{a}-86 \mathrm{c}}{559}<0 \text { and }
$$

$\left(x_{i}^{* * *}-q_{i}^{* * *}\right)-\left(x_{i}^{* * * *}-q_{i}^{* * * *}\right)=\frac{2 a-2 c}{13}>0$. Thus, we can obtain $x_{i}^{* * *}-q_{i}^{* * *}>x_{i}^{* * * *}-q_{i}^{* * * *}>x_{i}^{*}-q_{i}^{*}>0$.

If $\mathrm{a}<\mathrm{c}<\frac{22 \mathrm{a}-5 \mathrm{~m}}{17}$, then $\mathrm{x}_{\mathrm{i}}^{* * * *}-\mathrm{q}_{\mathrm{i}}^{* * * *}=\frac{2 \mathrm{c}-\mathrm{a}-\mathrm{m}}{13}>0,\left(\mathrm{x}_{\mathrm{i}}^{*}-\mathrm{q}_{\mathrm{i}}^{*}\right)-\left(\mathrm{x}_{\mathrm{i}}^{* * * *}-\mathrm{q}_{\mathrm{i}}^{* * * *}\right)=\frac{30 \mathrm{~m}+56 \mathrm{a}-86 \mathrm{c}}{559}<0$, and $\left(\mathrm{x}_{\mathrm{i}}^{* * *}-\right.$ $\left.\mathrm{q}_{\mathrm{i}}^{* * *}\right)-\left(\mathrm{x}_{\mathrm{i}}^{* * * *}-\mathrm{q}_{\mathrm{i}}^{* * * *}\right)=\frac{2 \mathrm{a}-2 \mathrm{c}}{13}<0$. Thus, we have $\mathrm{x}_{\mathrm{i}}^{* * *}-\mathrm{q}_{\mathrm{i}}^{* * *}>\mathrm{x}_{\mathrm{i}}^{* * * *}-\mathrm{q}_{\mathrm{i}}^{* * * *}>\mathrm{x}_{\mathrm{i}}^{*}-\mathrm{q}_{\mathrm{i}}^{*}>0$.

\section{Appendix B: Proof of Proposition 2}

The following can be derived if $a>m$ and $\frac{7 a+10 m}{17}<c<\frac{22 a-5 m}{17}$ :

Since $\pi_{i}^{*}-\pi_{i}^{* *}=\frac{-400(a-m)^{2}}{31433}<0, \pi_{i}^{*}-\pi_{i}^{* * *}=\frac{6900(a-m)^{2}}{312481}>0$ and $\pi_{i}^{* *}-\pi_{i}^{* * *}=\frac{100(a-m)^{2}}{2873}>0$, we have $\pi_{i}^{* *}>$ $\pi_{i}^{*}>\pi_{i}^{* * *}$ and $\pi_{i}^{* *}-\pi_{i}^{* * * *}=\frac{4(2 a+15 m-17 c)^{2}}{25857}>0$, i.e., $\pi_{i}^{* *}>\pi_{i}^{* * * *}$.

Since $\sqrt{\pi_{j}^{*}}-\sqrt{\pi_{j}^{* *}}=\frac{80 a-80 m}{2193}>0, \sqrt{\pi_{j}^{*}}-\sqrt{\pi_{j}^{* * *}}=\frac{-40 a+40 m}{1677}<0$ and $\sqrt{\pi_{j}^{* *}}-\sqrt{\pi_{j}^{* * *}}=\frac{-40 a+40 m}{633}<0$, we have $\pi_{j}^{* * *}>\pi_{j}^{*}>\pi_{j}^{* *}$.

If $\frac{7 a+10 m}{17}<c<\frac{28 a+15 m}{43}, \pi_{i}^{*}-\pi_{i}^{* * * *}=\frac{-4(28 a+15 m-43 c)(304 a-1035 m+731 c)}{2812329}<0$, and we have $\pi_{i}^{* *}>\pi_{i}^{* * * *}>\pi_{i}^{*}>$ 
$\pi_{i}^{* * *}, \sqrt{\pi_{j}^{* *}}-\sqrt{\pi_{j}^{* * * *}}=\frac{16 a+120 m-136 c}{1989}<0$, and $\sqrt{\pi_{j}^{*}}-\sqrt{\pi_{j}^{* * * *}}=\frac{224 a+120 m-344 c}{5031}>0$, so we have $\pi_{j}^{* * *}>\pi_{j}^{*}>\pi_{j}^{* * * *}>$ $\pi_{j}^{* *}$.

If $\frac{28 a+15 m}{43}<c<a$, then $\pi_{i}^{*}-\pi_{i}^{* * * *}=\frac{-4(28 a+15 m-43 c)(304 a-1035 m+731 c)}{2812329}>0$ and $\pi_{i}^{* * *}-\pi_{i}^{* * * *}=$ $\frac{-4(a-c)(13 a-30 m+17 c)}{1521}<0$. Thus, we have $\pi_{i}^{* *}>\pi_{i}^{*}>\pi_{i}^{* * * *}>\pi_{i}^{* * *}, \sqrt{\pi_{j}^{*}}-\sqrt{\pi_{j}^{* * * *}}=\frac{224 a+120 m-344 c}{5031}<0, \sqrt{\pi_{j}^{* * *}}-$ $\sqrt{\pi_{j}^{* * * *}}=\frac{8 a-8 c}{117}>0$, and $\pi_{j}^{* * *}>\pi_{j}^{* * * *}>\pi_{j}^{*}>\pi_{j}^{* *}$.

If $a<c<\frac{22 a-5 m}{17}$, then $\pi_{i}^{* * *}-\pi_{i}^{* * * *}=\frac{-4(a-c)(13 a-30 m+17 c)}{1521}>0$, and we have $\pi_{i}^{* *}>\pi_{i}^{*}>\pi_{i}^{* * *}>\pi_{i}^{* * * *} \cdot \sqrt{\pi_{j}^{* * *}}-$ $\sqrt{\pi_{j}^{* * * *}}=\frac{8 a-8 c}{117}<0$, and we can obtain $\pi_{j}^{* * * *}>\pi_{j}^{* * *}>\pi_{j}^{*}>\pi_{j}^{* *}$.

\section{Appendix C: Proof of Proposition 3}

Given $a>m$ and $\frac{7 a+10 m}{17}<c<\frac{22 a-5 m}{17}$, we can deduce the following results:

Since $C S_{U}^{*}-C S_{U}^{* *}=\frac{37600(a-m)^{2}}{534361}>0, C S_{U}^{*}-C S_{U}^{* * *}=\frac{-16400(a-m)^{2}}{312481}<0$ and $C S_{U}^{* *}-C S_{U}^{* * *}=\frac{-6000(a-m)^{2}}{48841}<0$, we have $C S_{U}^{* * *}>C S_{U}^{*}>C S_{U}^{* *}$. Since $C S_{D}^{*}-C S_{D}^{* *}=\frac{-320(a-m)(261 a+470 m-731 c)}{4809249}>0, C S_{D}^{*}-C S_{D}^{* * *}=$ $\frac{160(a-m)(149 a+410 m-559 c)}{2812329}<0$ and $C S_{D}^{* *}-C S_{D}^{* * *}=\frac{160(a-m)(71 a+150 m-221 c)}{439569}<0$, we have $C S_{D}^{* * *}>C S_{D}^{*}>C S_{D}^{* *}$.

If $\frac{7 a+10 m}{17}<c<\frac{28 a+15 m}{43}$, then $C S_{U}^{* *}-C S_{U}^{* * * *}=\frac{16(2 a+16 m-17 c)(191 a-225 m+34 c)}{439569}<0$ and $C S_{U}^{*}-C S_{U}^{* * * *}=$ $\frac{16(28 a+15 m-43 c)(529 a-615 m+86 c)}{2812329}>0$; thus, we have $C S_{U}^{* * *}>C S_{U}^{*}>C S_{U}^{* * * *}>C S_{U}^{* *}, C S_{D}^{* *}-C S_{D}^{* * * *}=$ $\frac{-32(281 a+450 m-731 c)(2 a+15 m-17 c)}{3956121}<0, C S_{D}^{*}-C S_{D}^{* * * *}=\frac{-32(28 a+15 m-43 c)(619 a+1230 m-1849 c)}{25310961}>0$, and $C S_{D}^{* * *}>C S_{D}^{*}>$ $C S_{D}^{* * * *}>C S_{D}^{* *}$

If $\frac{28 a+15 m}{43}<c<a$, we can obtain $C S_{U}^{*}-C S_{U}^{* * * *}=\frac{16(28 a+15 m-43 c)(529 a-615 m+86 c)}{2812329}<0$ and $C S_{U}^{* * *}-C S_{U}^{* * * *}=$ $\frac{16(a-c)(13 a-15 m+2 c)}{1521}>0$; then, $C S_{U}^{* * *}>C S_{U}^{* * * *}>C S_{U}^{*}>C S_{U}^{* *}, C S_{D}^{*}-C S_{D}^{* * * *}=\frac{-32(28 a+15 m-43 c)(619 a+1230 m-1849 c)}{25310961}<0$, $C S_{D}^{* * *}-C S_{D}^{* * * *}=\frac{-32(a-c)(13 a+30 m-43 c)}{13689}>0$, and $C S_{D}^{* * *}>C S_{D}^{* * * *}>C S_{D}^{*}>C S_{D}^{* *}$.

If $a<c<\frac{22 a-5 m}{17}$, then $C S_{U}^{* * *}-C S_{U}^{* * * *}=\frac{16(a-c)(13 a-15 m+2 c)}{1521}<0$, and we have $C S_{U}^{* * * *}>C S_{U}^{* * *}>C S_{U}^{*}>C S_{U}^{* *}$. $C S_{D}^{* * *}-C S_{D}^{* * * *}=\frac{-32(a-c)(13 a+30 m-43 c)}{13689}<0$, and we can obtain $C S_{D}^{* * * *}>C S_{D}^{* * *}>C S_{D}^{*}>C S_{D}^{* *}$.

\section{Appendix D: Proof of Proposition 4}

The following can be derived if $a>m$ and $\frac{7 a+10 m}{17}<c<\frac{22 a-5 m}{17}$ :

Since $S W_{U}^{*}-S W_{U}^{* *}=\frac{24000(a-m)^{2}}{534361}>0, S W_{U}^{*}-S W_{U}^{* * *}=\frac{-200(a-m)^{2}}{24037}<0$ and $S W_{U}^{* *}-S W_{U}^{* * *}=\frac{-200(a-m)^{2}}{3757}<0$, we have $S W_{U}^{* * *}>S W_{U}^{*}>S W_{U}^{* *}$.

If $\frac{10 a+7 m}{17}<c<\frac{28 a+15 m}{43}$, then $S W_{U}^{* *}-S W_{U}^{* * * *}=\frac{8(32 a-15 m-17 c)(2 a+15 m-17 c)}{33813}<0, S W_{U}^{*}-S W_{U}^{* * * *}=$ $\frac{8(58 a-15 m-43 c)(28 a+15 m-43 c)}{216333}>0$, and $S W_{U}^{* * *}>S W_{U}^{*}>S W_{U}^{* * *}>S W_{U}^{* *}$.

If $\frac{28 a+15 m}{43}<c<\frac{22 a-5 m}{17}$, then $S W_{U}^{*}-S W_{U}^{* * * *}=\frac{8(58 a-15 m-43 c)(28 a+15 m-43 c)}{216333}<0, S W_{U}^{* * *}-S W_{U}^{* * * *}=\frac{8(a-c)^{2}}{117}>0$, and $S W_{U}^{* * *}>S W_{U}^{* * * *}>S W_{U}^{*}>S W_{U}^{* *}$.

\section{Appendix E: Proof of Proposition 5}

The following can be derived if $a>m$ and $\frac{7 a+10 m}{17}<c<\frac{22 a-5 m}{17}$ :

The social welfare of the downstream industry can be compared by radical values. Since $\sqrt{S W_{D}^{*}}-\sqrt{S W_{D}^{* *}}=$ $\frac{160 a-160 m}{2193}>0, \sqrt{S W_{D}^{*}}-\sqrt{S W_{D}^{* * *}}=\frac{-80 a+80 m}{1677}<0$, and $\sqrt{S W_{D}^{* *}}-\sqrt{S W_{D}^{* * *}}=\frac{-80 a+80 m}{633}<0$, we have $S W_{D}^{* * *}>S W_{D}^{*}>$ $S W_{D}^{* *}$

If $\frac{7 a+10 m}{17}<c<\frac{28 a+15 m}{43}$, then $\sqrt{S W_{D}^{* *}}-\sqrt{S W_{D}^{* * * *}}=\frac{32 a+240 m-272 c}{1989}<0, \sqrt{S W_{D}^{*}}-\sqrt{S W_{D}^{* * * *}}=\frac{448 a+240 m-688 c}{5031}>$ 0, and $S W_{D}^{* * *}>S W_{D}^{*}>S W_{D}^{* * * *}>S W_{D}^{* *}$.

If $\frac{28 a+15 m}{43}<c<a$, then $\sqrt{S W_{D}^{*}}-\sqrt{S W_{D}^{* * * *}}=\frac{448 a+240 m-688 c}{5031}<0, \sqrt{S W_{D}^{* * *}}-\sqrt{S W_{D}^{* * * *}}=\frac{16 a-16 c}{117}>0$, and $S W_{D}^{* * *}>S W_{D}^{* * * *}>S W_{D}^{*}>S W_{D}^{* *}$.

If $a<c<\frac{22 a-5 m}{17}, \sqrt{S W_{D}^{* * *}}-\sqrt{S W_{D}^{* * * *}}=\frac{16 a-16 c}{117}<0$, and we have $S W_{D}^{* * * *}>S W_{D}^{* * *}>S W_{D}^{*}>S W_{D}^{* *}$. 
Junlong Chen, Yajie Wang, Jiali Liu. Capacity Choice and Government Regulation in a Vertical Industry

\section{Appendix F: Proof of Proposition 6}

The following can be derived if $a>m$ and $\frac{7 a+10 m}{17}<c<\frac{22 a-5 m}{17}$ :

0 .

$S W_{T}^{*}-S W_{T}^{* * * *}=\frac{-8(28 a+15 m-43 c)^{2}}{216333}<0, S W_{T}^{* *}-S W_{T}^{* * * *}=\frac{-8(2 a+15 m-17 c)^{2}}{33813}<0$, and $S W_{T}^{* * *}-S W_{T}^{* * * *}=\frac{-8(a-c)^{2}}{117}<$

If $\frac{7 a+10 m}{17}<c<\frac{19 a+15 m}{34}, S W_{T}^{*}-S W_{T}^{* *}=\frac{-160(a-m)(281 a+450 m-731 c)}{1603083}>0, S W_{T}^{* *}-S W_{T}^{* * *}=$

$\frac{40(a-m)(19 a+15 m-34 c)}{11271}>0$, and $S W_{T}^{* * * *}>S W_{T}^{*}>S W_{T}^{* *}>S W_{T}^{* * *}$.

If $\frac{19 a+15 m}{34}<c<\frac{71 a+15 m}{86}, S W_{T}^{*}-S W_{T}^{* * *}=\frac{40(a-m)(71 a+15 m-86 c)}{72111}>0, S W_{T}^{* *}-S W_{T}^{* * *}=\frac{40(a-m)(19 a+15 m-34 c)}{11271}<0$, and $S W_{T}^{* * * *}>S W_{T}^{*}>S W_{T}^{* * *}>S W_{T}^{* *}$.

If $\frac{71 a+15 m}{86}<c<\frac{22 a-5 m}{17}$, then $S W_{T}^{*}-S W_{T}^{* * *}=\frac{40(a-m)(71 a+15 m-86 c)}{72111}<0, S W_{T}^{*}-S W_{T}^{* *}=$ $\frac{-160(a-m)(281 a+450 m-731 c)}{1603083}>0$, and $S W_{T}^{* * * *}>S W_{T}^{* * *}>S W_{T}^{*}>S W_{T}^{* *}$.

\section{Acknowledgements}

The work is supported by the National Social Science Fund in the Later Stage of China (Grant number: 20FJYB066).

\section{References}

Barcena-Ruiz, J. C., \& Garzon, M. B. (2010). Endogenous timing in a mixed duopoly with capacity choice. The Manchester School, 78(2), 93-109. https://doi.org/10.1111/j.1467-9957.2009.02137.x

Basu, S. (1996). Procyclical productivity: increasing returns or cyclical utilization? The Quarterly Journal of Economics, 111(3), 719-751. https://doi.org/10.2307/2946670

Basu, S., Fernald, J. G., \& Shapiro, M. D. (2001). Productivity growth in the 1990s: technology, utilization, or adjustment? Carnegie-Rochester Conference Series on Public Policy, 55(1), 117-165. https://doi.org/10.1016/S0167-2231 (01)00054-9

Chen, J., Liu, J., Long Y., \& Luo J. (2019). Medicine pricing, optimal patent length and social welfare. Revista De Cercetare Si Interventie Sociala, 67, 352-365. https://doi.org/10.33788/rcis.64.26

Chen, J., Liu, J., Mo F., \& Xu L. (2019). The optimal proportion of employee stock in the duopoly competition. Transformations in Business \& Economics, 18(3C), 512-529.

Chen, J., Liu, J., Qin J. (2019). Corporate social responsibility and capacity selection. Transformations in Business \& Economics, 18(3C), 530-545.

Chen, J., Liu, R., Niu, Y., \& Zhu, J. (2019). Impact of product heterogeneity and soft budget constraint on excess capacity in Chinese energy industry based on the duopoly model. Chinese Journal of Population Resources and Environment, 17(2), 123-134. https://doi.org/10.1080/10042857.2019.1574459

Chen, J., Tang, H., \& Liu, J. (2019). Duopoly, optimal proportion of state-owned shares and international cross-ownership. Revista De Cercetare Si Interventie Sociala, 64, 352-365. https://doi.org/10.33788/rcis.64.26

Chen, J., Wang, X., Chu, Z. (2020). Capacity sharing, product differentiation and welfare. Economic Research-Ekonomska Istrazivanja, 33(1), 107-123.https://doi.org/110.1080/1331677X.2019.1710234

Chen, J., Wang, M., Gao, Y., \& Long, Y. (2019). Duopoly, mixed ownership, and the optimal proportion of employee stocks in state-owned enterprises in China. Managerial and Decision Economics, 40, 550-558. https://doi.org/10. 1002/mde.3025.

Chen, J., Xie, X., Liu, J. (2020). Capacity sharing with different oligopolistic competition and government regulation in a supply chain. Managerial and Decision Economics, 41(1), 79-92. https://doi.org/10.1002/mde.3094

Chen, J., Yang, R., \& Li, L. (2017). Cross ownership, social welfare and government regulations in a vertical bilateral monopoly market, Finance and Trade Research, 8, 11-22. https://doi.org/10.19337 /j.cnki.34-1093/f.017.08.002

Dagdeviren, H. (2016). Structural constraints and excess capacity: an international comparison of manufacturing firms. Development Policy Review, 34(5), 623-641. https://doi.org/10.1111/dpr.12168

Dagdeviren, H., \& Mahran, H. A. (2010). A tale of industrial stagnation from Africa. International Review of Applied Economics, 24(4), 495-510. https://doi.org/10.1080/02692171.2010.483792

Dixit, A. K., \& Stiglitz, J. E. (1977). Monopolistic competition and optimum product diversity. The American economic review, 67(3), 297-308. https://doi.org/10.1016/0309-586X(77)90015-2

Elhadj, N. B., Jebsi, K., \& Lahmandi-Ayed, R. (2012). Quality and capacity choices in a vertical differentiation model with congestion. International Journal of Economic Theory, 8(3), 259-275. https://doi.org/10.1111/j.17427363.2012.00190.x 
Eso, P., Nocke, V., \& White, L. (2010). Competition for scarce resources. The RAND Journal of Economics, 41(3), 524548. https://doi.org/10.1111/j.1756-2171.2010.00110.x

Fagnart, J. F., Licandro, O., \& Portier, F. (1999). Firm heterogeneity, capacity utilization, and the business cycle. Review of Economic Dynamics, 2(2), 433-455. https://doi.org/10.1006/redy.1998.0057

Fanea-Ivanovici, M., Radu-Cristian, M., Marius-Cristian, P., et al. (2019). Fighting corruption and enhancing tax compliance through digitization: achieving sustainable development in Romania. Sustainability, 11(5), 1480. https://doi.org/10.3390/su11051480

Fanti, L. (2016). Social welfare and cross-ownership in a vertical industry: When the mode of competition matters for antitrust policy. Japan and the World Economy, 37, 8-16. https://doi.org/10.1016/j.japwor.2016.02.004

Fernandez-Ruiz, J. F. (2012). Capacity choice in a mixed duopoly with a foreign competitor. Economics Bulletin, 32, 26532661.

Ghosh, A., Morita, H., \& Wang, C. (2014). Horizontal mergers in the presence of vertical relationships. MPRA Paper. https://doi.org/10.2139/ssrn.2529687

Jain, A., \& Bala, R. (2018). Differentiated or integrated: Capacity and service level choice for differentiated products. European Journal of Operational Research, 266(3), 1025-1037. https://doi.org/10.1016/j.ejor.2017.10.053

Kornai, J. (1980). Economics of shortage. Amsterdam:North-Holland.

Lavrutich, M. N. (2017). Capacity choice under uncertainty in a duopoly with endogenous exit. European Journal of Operational Research, 258(3), 1033-1053. https://doi.org/10.1016/j.ejor.2016.09.048

Lee, J. Y., \& Wang, L. F. (2018). Foreign competition and optimal privatization with excess burden of taxation. Journal of Economics, 125(2), 189-204. https://doi.org/ 10.1007/s00712-017-0592-y

Lommerud, K. E., Straume, O. R., \& Sorgard, L. (2005). Downstream merger with upstream market power. European Economic Review, 49(3), 717-743. https://doi.org/10.1016/S0014-2921(03)00068-0

Lu, Y., \& Poddar, S. (2006). The choice of capacity in mixed duopoly under demand uncertainty. The Manchester School, 74(3), 266-272. https://doi.org/10.1111/j.1467-9957.2006.00492.x

Lu, Y., \& Poddar, S. (2009). Endogenous timing in a mixed duopoly and private duopoly-'capacity-then-quantity' game: the linear demand case. Australian Economic Papers, 48(2), 138-150. https://doi.org/10.1111/j.1467-8454.2009.00369.x

Manasakis, C., \& Vlassis, M. (2013). Downstream mode of competition with upstream market power. Research in Economics, 68(1), 84-93. https://doi.org/10.1016/j.rie.2013.12.002

Murphy, D. (2017). Excess capacity in a fixed-cost economy. European Economic Review, 91, 245-260. https://doi.org/10.1016/j.euroecorev.2016.11.002

Nakamura, Y. (2014). Capacity choice in a duopoly with a consumer-friendly firm and an absolute profit-maximizing firm. International Review of Economics \& Finance, 34, 105-117. https://doi.org/10.1016/j.iref.2014.07.004

Nakamura, Y., \& Saito, M. (2013). Capacity choice in a price-setting mixed duopoly: The relative performance approach. Modern Economy, 4(4), 124-133. https://doi.org/10.4236/tel.2013.32020

Nie, P. Y., \& Chen, Y. H. (2012). Duopoly competitions with capacity constrained input. Economic Modelling, 29(5), 17151721. https://doi.org/10.1016/j.econmod.2012.05.022

Nie, P. Y. (2014). Effects of capacity constraints on mixed duopoly. Journal of Economics, 112(3), $283-294$. https://doi.org/10.1007/s00712-013-0362-4

Nie, P. Y., \& Wang, C. (2019). An analysis of cost-reduction innovation under capacity constrained inputs. Applied Economics, 51(6), 564-576. https://doi.org/10.1080/00036846.2018.1497850

Nishimori, A., \& Ogawa, H. (2004). Do firms always choose excess capacity? Economics Bulletin, 12(2), 1-7.

Ogawa, H. (2006). Capacity choice in the mixed duopoly with product differentiation. Economics Bulletin, 12(8), 1-6.

Robles, J. (2011). Demand growth and strategically useful idle capacity. Oxford Economic Papers, 63(4), 767-786. https://doi.org/10.1093/oep/gpr033

Symeonidis, G. (2010). Downstream merger and welfare in a bilateral oligopoly. International Journal of Industrial Organization, 28(3), 230-243. https://doi.org/10.1016/j.ijindorg.2009.08.004

Tao, A., Wang, X. H., \& Yang, B. Z. (2018). Duopoly models with a joint capacity constraint. Journal of Economics, 125(2), 159-172. https://doi.org/10.1007/s00712-018-0597-1

Tomaru, Y., Nakamura, Y., \& Saito, M. (2009). Capacity choice in a mixed duopoly with managerial delegation. Economics Bulletin, 29(3), 1904-1924.

Tomaru, Y., Nakamura, Y., \& Saito, M. (2011). Strategic managerial delegation in a mixed duopoly with capacity choice: partial delegation or full delegation. The Manchester School, 79(4), 811-838. https://doi.org/10.1111/j.14679957.2010.02179.x

Vives, X. (1986). Commitment, flexibility and market outcomes. International Journal of Industrial Organization, 4(2), 217-229. https://doi.org/10.1016/0167-7187(86)90032-9 
Junlong Chen, Yajie Wang, Jiali Liu. Capacity Choice and Government Regulation in a Vertical Industry

Wen, M., \& Sasaki, D. (2001). Would excess capacity in public firms be socially optimal? Economic Record, 77(238), 283290. https://doi.org/10.1111/1475-4932.t01-1-00023

Yu, D., \& Lu, Y., (2015). Government improper intervention and overcapacity of strategic emerging industrie-a case study of chinese photovoltaic industry. China Industrial Economics. 10, 53-68. https://doi.org/1006-480X(2015)10-0053-16

Ziss, S. (1995). Vertical separation and horizontal mergers. The Journal of Industrial Economics, 43(1), 63-75. https://doi.org/10.2307/2950425

The article has been reviewed.

Received in February 2020; accepted in December 2020. 